\title{
Four-Week Pedometer-Metered Step Walking Decreases Waist and Hip Circumference in Healthy College Students: A Pilot Study
}

\author{
Lauren Meeks ${ }^{1}$, Andy Reynaga ${ }^{1}$, Corinne Worland ${ }^{1}$, Edward Jo ${ }^{1}$, Sarah Dunn ${ }^{2}$, Michelle Wien ${ }^{1}$, \\ and Bonny Burns-Whitmore ${ }^{1}$ \\ ${ }^{1}$ California State Polytechnic University, Pomona, CA, USA \\ ${ }^{2}$ University of La Verne, La Verne, CA, USA
}

\begin{abstract}
Background and Purpose: Positive effects of pedometer-metered steps and motivation on body composition have not been documented in healthy adults. This study determined the effects of: 1) 4weeks of pedometer-metered walking and steps on body composition, fasting blood glucose (FBG), blood pressure (BP), diet changes, waist-to-hip ratios (WHR), and 2) daily motivation on step count. Methods: For 4-weeks, participants ( $\mathrm{n}=29,24 \pm 3$.8yo) wore a pedometer and recorded daily steps. Subjects were randomized into two groups: 1) daily motivational quotes (MQ) $(n=19)$ to determine changes in step counts and 2) a control group (no MQ). Measurements were performed baseline, at study end; and 3 randomized 3-day diet records were collected. Results: Waist and hip circumference decreased significantly ( $\mathrm{p}=0.002 \& \mathrm{p}=0.03$ ) in both groups and decreased fat free mass (FFM) approached significance $(\mathrm{p}=0.06)$. Decreased fruit intake was observed in the second $(\mathrm{p}=0.007)$ and third $(\mathrm{p}=0.023)$ diet records. Conclusion: Motivation did not increase steps or changes in FBG and BP. However, WHR decreased in both groups suggesting that 4-weeks of pedometer walking results in positive abdominal changes. Additional longer-term studies are needed to examine these physical changes as well as investigate the decreased fruit intake.
\end{abstract}

(C) 2017 Californian Journal of Health Promotion. All rights reserved.

Keywords: step walking, waist-to-hip ratios, blood pressure, blood glucose

\section{Introduction}

The incidence of obesity and overweight adults $\left(\mathrm{BMI}>25 \mathrm{~kg} / \mathrm{m}^{2}\right.$ ) in the United States (US) has dramatically increased in the past three decades (77\% for adults) (Skelton, Cook, Auinger, Klein, \& Barlow, 2009; Wang, Beydoun, Liang, Caballero, \& Kumanyika, 2008). Trends indicate the projected obesity prevalence will be $86.3 \%$ for adults in 2030 (Wang et al., 2008). Increases in overweight and obesity prevalence also increases obesity-associated health risks such as coronary heart disease, myocardial infarction, cardiovascular disease (CVD), stroke, and type 2 diabetes (Dubinina et al., 2014; Mitchell et al., 2015; Rheaume et al., 2014). The high prevalence of obesity-associated disease risk raises US health care costs, by a projected 861 to 957-billion-dollar expenditure by 2030 (16-18\% of total health care costs) (Wang et al., 2008). Projected trends estimate that 65 million adult obesity cases will occur by 2030 (C. Wang et al.,
2011; Y. Wang et al., 2008).

Physical activity (PA) decreases obesity prevalence by decreasing weight and fat mass (FM) and reducing the risk of chronic diseases in individuals by means of a dose-response relationship (Hu et al., 1999; Slentz et al., 2004). Energy expended during PA may result in a negative energy balance in the body, which results in FM utilization and reduction over time (Aadland, Jepsen, Andersen, \& Anderssen, 2014; Slentz et al., 2004). Additional benefits include reduced cholesterol levels and blood pressure (BP) levels and increased insulin sensitivity; all of which results in improved glucose tolerance and decreased risk of CVD and type 2 diabetes (Anderson, Odell, Wilson, \& Kannel, 1991; Helmrich, Ragland, Leung, \& Paffenbarger Jr, 1991). Inadequate PA is associated with $11 \%$ of health care costs in the US (Carlson, Fulton, Pratt, Yang, \& Adams, 2015). 
Although the benefits of PA have been wellestablished, many Americans do not engage in PA on a regular basis due to lack of motivation to begin and maintain exercise programs (Stanely, Cumming, Standage, \& Duda, 2012). The amount of PA required for a decrease in weight to occur is modest, as the American College of Sports Medicine and the Center for Disease Control and Prevention recommends 30 minutes of brisk walking five days a week for weight maintenance benefits (Haskell et al., 2007; Montesi, Moscatiello, Malavolti, Marzochhi, \& Marchesini, 2013). Walking is a universal PA that easily transitions one from a sedentary to a more active lifestyle due to the low impact and injury rate (Montesi et al., 2013). However, it appears that some type of motivation is still needed in order to start and maintain a walking program. It is estimated that $50 \%$ of people who start an exercise program quit in the first six months due to lack of motivation (Stanely et al., 2012). Research has shown that different types of motivation are effective in helping people initiate and sustain PA, such as autonomous and external motivation (Brunet, Gunnell, Gaudreau, \& Sabiston, 2015; Dumitrescu \& Otoiu, 2014). The key to success of any motivational method for engaging in PA is perceived confidence in one's ability to perform the PA (Dumitrescu \& Otoiu, 2014; Parfitt, Olds, \& Eston, 2015). There are no studies that have investigated motivation as it relates to the use of pedometers to increase PA.

Meta-analysis research shows that weight loss programs have incorporated the use of pedometers as a means of autonomous motivation to engage in PA and also maintain an exercise regime (Richardson et al., 2008). Such programs have resulted in modest weight loss without dietary intervention (Richardson et al., 2008). Previous research has shown that body weight and FM loss occurs in overweight individuals who walk for at least 30 minutes per day, five days per week for at least four weeks, and that the number of weeks spent walking is positively correlated with the amount of weight lost (Bond, Perry, Parker, Robinson, \& Burnett, 2002; Richardson et al., 2008). Prior studies have also tested the relationship between walking and other health variables indicative of diseases associated with obesity, specifically waist circumference, BP, dietary choices, and blood glucose levels without the use of pedometers (Gilson, McKenna, Puig-Ribera, Brown, \& Burton, 2009; Tieland et al., 2012). Previous research, however, has not examined the relationship between the use of a pedometer while walking and the effects on weight loss and other body composition variables in addition to waist-to-hip ratio (WHR), BP, diet choices, and fasting blood glucose (FBG) levels in healthy adults $\left(18.5<\mathrm{BMI}<25.0 \mathrm{~kg} / \mathrm{m}^{2}\right)$ during a 4 -week period.

The research regarding use of pedometers is lacking in many areas. Pedometers can measure the number of steps taken per day, but very little research has used them as a means of determining PA. There is no research that has looked at step walking and body composition changes, including WHR in healthy adults $\left(18.5<\mathrm{BMI}<25.0 \quad \mathrm{~kg} / \mathrm{m}^{2}\right) \quad$ while using pedometers. No one has looked at diet changes that occur when people begin a PA program that uses pedometers to our knowledge.

Therefore, we propose to provide daily motivational quotes to the 'intervention' group to determine if motivation influences the number of steps taken by healthy adults. We are also investigating the effects of step walking, as tracked by pedometer usage, on body composition changes, WHR, BP, FBG, and diet choices in adults of healthy weight that belong to the intervention group, as well as the control group that does not receive daily motivation, over a 4-week period.

\section{The Current Study}

The objective of this exploratory pilot intervention was to discover if pedometermetered walking had an effect on the following health characteristics within a 4-week period in healthy young adult (18-45-year-old) participants: body composition, FBG, BP, dietary choices, and WHR. This study tested if receiving daily motivational quotes (intervention group) as an external motivational source resulted in a significant increase in the number of steps walked per day compared to solely 
using a pedometer as a motivational source. Two hypotheses were proposed for this study: 1) pedometer-metered walking results in significantly increased fat free mass (FFM), decreased fat mass, FBG, BP, and WHR, and a positive change in diet choices from baseline; 2) external motivation provided by daily quotes (intervention group) increases the average number of steps walked per day.

\section{Methods}

\section{Study Design}

The study was a randomized trial (interventionreceiving motivational quotes, versus not receiving motivational quotes-control) that consisted of a 4-week intervention pilot study and the length was determined based on previous research observations of body composition changes within a 4-week period
(Bakuradze et al., 2014; Edholm et al., 2015). All subjects participated in a lead-in week to obtain baseline anthropometric, clinical and laboratory measurement data.

The participants were randomized into two groups. Treatment one $(\mathrm{N}=19)$ was the Motivational Quote (MQ) intervention group, and the participants received an email every morning through Blackboard ${ }^{\circledR}$ (Blackboard Inc., Washington, D.C., USA) that encouraged the participants to increase the number of steps that they walked per day. The emails consisted of inspirational quotes that included the words "step" or "walking" or ideas for activities to increase the number of steps walked per day (Table 1a and 1b). Treatment two $(\mathrm{N}=10)$ was the no MQ (control) group and did not receive daily motivational quotes.

Table 1a.

Motivational Quotes/Sayings Emailed Daily to Intervention Group (N=19)

\begin{tabular}{|c|c|}
\hline Day & Motivational Quote/Saying \\
\hline Day 1 & $\begin{array}{l}\text { Do the difficult things while they are easy and do the great things while they are small. A journey of a } \\
\text { thousand miles must begin with a single step. -Lao Tzu }\end{array}$ \\
\hline Day 2 & Setting goals is the first step in turning the invisible into the visible. -Tony Robbins \\
\hline Day 3 & The first step is you have to say that you can. -Will Smith \\
\hline Day 4 & Step with care and great tact, and remember that Life's a Great Balancing Act. -Dr. Seuss \\
\hline Day 5 & Trying to think of new ways to walk more? Try parking in the furthest spot in the parking lot! \\
\hline Day 6 & You will either step forward into growth, or you will step backward into safety. -Maslow \\
\hline Day 7 & Need another walking idea? During down time between classes, explore the campus! \\
\hline Day 8 & $\begin{array}{l}\text { Develop an attitude of gratitude, and give thanks for everything that happens to you, knowing that every } \\
\text { step forward is a step toward achieving something bigger and better than your current situation. -Brian } \\
\text { Tracy }\end{array}$ \\
\hline Day 9 & Try exercising more often to increase the number of steps you walk per day! \\
\hline Day 10 & $\begin{array}{l}\text { Human progress is neither automatic nor inevitable... Every step toward the goal of justice requires } \\
\text { sacrifice, suffering, and struggle; the tireless exertions and passionate concern of dedicated individuals. - } \\
\text { Martin Luther King, Jr. }\end{array}$ \\
\hline Day 11 & Walking not only benefits your body, but it refreshes the mind and soul. \\
\hline Day 12 & $\begin{array}{l}\text { Life is the most exciting opportunity we have. But we have one shot. You graduate from college once, } \\
\text { and that's it. You're going out of that nest. And you have to find that courage that's deep, deep, deep in } \\
\text { there. Every step of the way. -Andrew Shue }\end{array}$ \\
\hline Day 13 & Competing with friends helps increase your motivation to walk more every day! \\
\hline Day 14 & $\begin{array}{l}\text { When adversity strikes, that's when you have to be the most calm. Take a step back, stay strong, stay } \\
\text { grounded and press on. -LL Cool J }\end{array}$ \\
\hline Day 15 & Congratulations! You are more than half way through the 4-week study! Keep up the great work! \\
\hline
\end{tabular}




\section{Table 1b (continuation of Table 1a).}

Motivational Quotes/Sayings Emailed Daily to Intervention Group (N=19)

\begin{tabular}{|c|c|}
\hline Day & Motivational Quote/Saying \\
\hline Day 16 & The first step towards knowledge is to know that we are ignorant. -Richard Cecil \\
\hline Day 17 & $\begin{array}{l}\text { The vision must be followed by the venture. It is not enough to stare up the steps - we must } \\
\text { step up the stairs. -Vance Havner }\end{array}$ \\
\hline Day 18 & $\begin{array}{l}\text { Acceptance of what has happened is the first step to overcoming the consequences of any } \\
\text { misfortune. -William James }\end{array}$ \\
\hline Day 19 & Trust is the first step to love. -Munshi Premchand \\
\hline Day 20 & $\begin{array}{l}\text { Have a bias toward action - let's see something happen now. You can break that big plan into } \\
\text { small steps and take the first step right away. -Indira Gandhi }\end{array}$ \\
\hline Day 21 & $\begin{array}{l}\text { Congratulations everyone! You only have } 1 \text { week left of recording your steps for this study! } \\
\text { Let's make the last week the best :) }\end{array}$ \\
\hline Day 22 & What saves a man is to take a step. Then another step. -Antoine De Saint-Exupery \\
\hline Day 23 & $\begin{array}{l}\text { The first step towards success is taken when you refuse to be a captive of the environment in } \\
\text { which you first find yourself. -Mark Caine }\end{array}$ \\
\hline Day 24 & $\begin{array}{l}\text { Discontent is the first step in progress. No one knows what is in him till he tries, and many } \\
\text { would never try if they were not forced to. -Basil W. Maturin }\end{array}$ \\
\hline Day 25 & $\begin{array}{l}\text { Success will never be a big step in the future, success is a small step taken just now. -Jonatan } \\
\text { Martensson }\end{array}$ \\
\hline Day 26 & $\begin{array}{l}\text { The indispensable first step to getting the things you want out of life is this: decide what you } \\
\text { want. -Ben Stein }\end{array}$ \\
\hline Day 27 & $\begin{array}{l}\text { Don't be afraid to take a big step if one is indicated; you can't cross a chasm in two small } \\
\text { jumps. -David Lloyd George }\end{array}$ \\
\hline Day 28 & $\begin{array}{l}\text { Congratulations!! Today is your last day recording your steps for this study! You made it } \\
\text { through the four weeks and have done an outstanding job. Thank you :) }\end{array}$ \\
\hline
\end{tabular}

\section{Participants}

This study was approved by the Institutional Review Board at a mid-sized southern Californian university in the California State University system. Informed consent was obtained from all of the participants prior to beginning the study. Forty healthy males and females between the ages of 18 and 45 years old were recruited between the first week of January 2015 through the third week of January 2015 using flyers and emails on campus. The inclusion criteria for the participants required that they were university students or staff, apparently healthy males or females between the ages of 18 and 45 years old, had no known chronic diseases, were not pregnant, did not have a pacemaker or other metal objects implanted in their body, and did not have any injuries that could be exacerbated by walking.
After signing the informed consent, the participants completed a health-screening questionnaire to estimate their current dietary intake and PA levels. The health-screening questionnaire is a modified questionnaire created by the Human Nutrition and Food Science Department at the university (BurnsWhitmore, Haddad, Sabaté, \& Rajaram, 2014). Of the 40 recruited subjects, 32 completed the study and 3 subjects were excluded due to failure of adhering to the study protocol $(\mathrm{N}=29)$.

\section{Measures and Procedures}

At the beginning of the study, each participant was provided with a Sportline $340 \AA$ pedometer to monitor the number of steps that they walked per day and was advised to increase the number of steps that they walked during the study period. The participants were asked to take a picture of their pedometer screen at the end of 
each day and upload that picture into a secure and confidential designated folder in the Blackboard® organization entitled "Step Walk Study".

The participants were also instructed to complete a 3-day diet record, which recorded their diet choices during the lead-in week as well as three 3-day diet records at random time points during the 4-week study period. The three-day self-reported records were utilized as valid predictors of usual dietary intake (Lassale et al., 2015; Walker, Bell, Boyd, \& Davies, 2013). The randomized time points for the diet data collection were determined using the website: www.randomizer.org. After completing each dietary record, the participants were instructed to upload their documents into the designated folder in the Blackboard ${ }^{\circledR}$ "Step Walk Study" organization. Participants were not instructed to alter their dietary intake, only to report their intakes during the 1-week lead-in and 4-week study periods. From the 29 participants ( 2 male, 27 females) who completed the study, only 20 (1 male, 19 females) completed the three dietary intake records.

\section{Measures and Procedures}

Data collection occurred during the lead-in week and weeks 1 and 4 in the morning hours between 6:30am and 11:00am. Participants were instructed to fast for at least 12 hours prior to each data collection. The following data were collected at baseline and end of study: FBG, BP, height, body composition, and waist and hip measurements. FBG measurements were obtained using a Freestyle Freedom Lite ${ }^{\circledR}$ glucometer and test strips. BP was measured using an automatic blood pressure monitor (Omron BP629 Automatic Wrist 3 Series ${ }^{\circledR}$ ). Height was obtained using a statiometer (SECA 214) and body composition (fat mass, fat free mass, and total body water) was measured using the Tanita Bioelectrical Impedance Analyzer ${ }^{\circledR}$ (BIA) (Tanita SC 300 S). The Tanita BIA is a validated method for accurate measurement of body composition (Gupta, Balasekaran, Govindaswamy, Hwa, \& Shun, 2011; Ritchie, Miller, \& Smiciklas-Wright, 2005). Waist and hip measurements were obtained following the World Health Organization (WHO, 2011) protocol and the waist-to-hip ratios were calculated from the waist and hip measurements. The research assistant used the lowest rib and midpoint between the lowest rib and the iliac crest for the waist measurements. For hip measurements, the research assistant used the widest area of the buttocks. Each measurement taken during the data collection was performed in duplicate to reduce human error.

\section{Statistical Analyses}

All data was analyzed with SPSS 20.0 for Windows (SPSS, Chicago, IL). Two-tailed paired T-test statistics were run on week 1 and week 4 for mean body composition, WHR, BP, and FBG data to determine if the tested variables significantly changed within four weeks $(\mathrm{N}=29)$. It was not necessary to control for total body water in the statistical analysis because the body composition output generated total body water content for each measurement. Diet data was entered into a dietary analysis program (ESHA ${ }^{\circledR}$ Food Processor Nutrition Analysis software, Salem, OR) to analyze the nutrient content of the collected diets. Repeated measures ANOVA statistical tests were run on the nutrient data to determine significant differences between the dietary choices in week 1 and week 4 for total calories, fruit, vegetable, simple sugar, potassium, calcium, sodium, carbohydrate, fat, and protein intake on the twenty complete records.

The Mann-Whitney U statistical test was performed on the average number of steps walked by the intervention (motivation) and control (no motivation) to determine any significant differences within four weeks $(\mathrm{N}=29)$. The Pearson's Correlation Coefficient test was run to discover if a relationship exists between the average number of steps walked per day and body composition, WHR, BP, FBG $(\mathrm{N}=29)$, and diet choices $(\mathrm{N}=20)$ within four weeks. Statistical significance was determined at $\mathrm{p} \leq 0.05$ for all analyses. Power for the two-tailed paired-T test was calculated as $74 \%$ based on the sample size $(\mathrm{N}=29)$ and alpha level $(\alpha=0.05)$ and power for the repeated measures ANOVA test was calculated as $49 \% \quad(\mathrm{~N}=20, \quad \alpha=0.05)$ (www.statpages.org, Iowa, USA). The calculated power for the Mann-Whitney $U$ test 
was 50\% (Intervention: $\mathrm{N}=19$; Control: $\mathrm{N}=10$; $\alpha=0.05)$ and for the Pearson's Correlation Coefficient test the power was $80 \%(\mathrm{~N}=29$, $\alpha=0.05)$.

\section{Results}

Significant decreases in waist circumference $(77.1 \pm 12 \mathrm{~cm}$ to $74.5 \pm 10.9 \mathrm{~cm}, \mathrm{p}=0.002)$ (absolute change $=-2.60 \pm 1.10 \mathrm{~cm}$, percent change $=-3.7 \pm 9.16 \%$ ) and hip circumference $(99.8 \pm 9.39 \mathrm{~cm}$ to $99.0 \pm 9.59 \mathrm{~cm}, \mathrm{p}=0.030)$ (absolute change $=-0.80 \pm 0.20 \mathrm{~cm}$, percent change $=-0.80 \pm 2.12 \%$ ) were observed from week one to week four (Table 2). Additionally, WHR decreased significantly over time $(0.77 \pm 0.08$ to $0.75 \pm 0.05, \mathrm{p}=0.054)$ (absolute change $=-0.02 \pm 0.03$, percent change $=-2.60 \pm 37.5 \%$ ) (Table 2). No significant changes were observed for body composition (total body weight, percent body fat, fat mass, and FFM), FBG, or BP in both the intervention (MQ) and control (no MQ) group (Table 2). However, there was a trend towards a significant decrease for FFM ( $p=0.060)$ at the end of the study in both groups.

Table 2.

Comparison of Mean Health Parameter Values Over Time for all Participants ${ }^{1}(\mathrm{~N}=29)$.

\begin{tabular}{|c|c|c|c|c|}
\hline Health Parameter & $\begin{array}{l}\text { Mean (SD)- } \\
\text { Week } 1\end{array}$ & $\begin{array}{l}\text { Mean (SD)- } \\
\text { Week } 4\end{array}$ & $\mathrm{t}$ & $\mathrm{p}$ \\
\hline Total body water & $0.33(0.04)$ & $0.32(0.04)$ & 1.045 & 0.305 \\
\hline Percent body fat (\%) & $27.8(0.10)$ & $28.1(8.33)$ & -1.001 & 0.325 \\
\hline Fat mass (kg) & $54.4(4.72)$ & $54.8(9.42)$ & -0.714 & 0.453 \\
\hline Fat free mass $(\mathrm{kg})$ & $45.3(5.56)$ & $44.9(5.18)$ & 1.960 & 0.060 \\
\hline Systolic blood pressure (mmHg) & $109(10.5)$ & $109(9.80)$ & -0.187 & 0.853 \\
\hline Diastolic blood pressure (mmHg) & $71.7(7.60)$ & $71.3(7.90)$ & 0.710 & 0.710 \\
\hline Fasting blood glucose (mg/dL) & $83.8(7.40)$ & $87.4(23.2)$ & -0.967 & 0.343 \\
\hline Waist circumference $(\mathrm{cm})$ & $77.1(12.0)$ & $74.5(10.9)$ & 3.492 & $0.002 *$ \\
\hline Hip circumference $(\mathrm{cm})$ & 99.8 (9.39) & 99.0 (9.59) & 2.286 & $0.030 *$ \\
\hline Waist-to-hip ratio & $0.77(0.08)$ & $0.75(0.05)$ & 2.014 & $0.054 *$ \\
\hline
\end{tabular}

The results of the repeated measures ANOVA on the diet data revealed a significant decrease in fruit intake in the second $(\mathrm{p}=0.007)$ and third $(p=0.023)$ dietary intake records compared to the baseline records (Table 3). The results were not significant for intake of vegetables, total calories, simple sugars, potassium, calcium, sodium, carbohydrates, fats, and protein among the three dietary intake records. The results of the Mann-Whitney U test showed no significant difference in the average number of steps walked between the intervention $(\mathrm{N}=19)$ and control group $(\mathrm{N}=10)$ during the four weeks (intervention mean steps per day $=7648 \pm 2480$, control mean steps per day $=9684 \pm 8374$, $\mathrm{p}=0.780$, percent change $=87.30 \pm 182.5$ ). The results of the Pearson's Correlation Coefficient test revealed no significant correlations between the average number of steps walked and body composition, BP, FBG, and WHR within four weeks ( $p>0.05$ ) (Table 4). 
Table 3.

Comparison of Mean Dietary Intake Records $(\mathrm{N}=20)$ at Three Random Time Points within the FourWeek Period

\begin{tabular}{lllllll}
\hline \multicolumn{7}{c}{ Mean Intake (SD) N=20 } \\
\hline Diet Record & 1 & 2 & 3 & $\begin{array}{l}\text { Effect } \\
\text { Size }\end{array}$ & $\begin{array}{l}\text { P-Value } \\
1-2\end{array}$ & $\begin{array}{l}\text { P-Value } \\
1-3\end{array}$ \\
\hline Total Calories (kcals) & $1794(498)$ & $1774(607)$ & $1640(580)$ & 0.061 & 1.000 & 0.842 \\
Simple Sugars (g) & $10.2(20.1)$ & $3.41(5.06)$ & $7.55(15.7)$ & 0.010 & 0.519 & 1.000 \\
Fruits (cup) & $3.08(1.03)$ & $2.20(0.96)$ & $2.40(1.00)$ & 0.318 & $0.007^{*}$ & $0.023^{*}$ \\
Vegetables (cup) & $2.18(0.84)$ & $2.10(1.05)$ & $1.82(0.79)$ & 0.194 & 1.000 & 0.137 \\
Sodium (mg) & $3028(1781)$ & $3180(2556)$ & $3006(1564)$ & 0.000 & 1.000 & 1.000 \\
Potassium (mg) & $1241(600)$ & $1233(681)$ & $1320(879)$ & 0.007 & 1.000 & 1.000 \\
Calcium (mg) & $632(229)$ & $639(298)$ & $687(325)$ & 0.019 & 1.000 & 1.000 \\
Protein (g) & $74.5(27.3)$ & $78.4(26.6)$ & $73.7(24.5)$ & 0.001 & 1.000 & 1.000 \\
Fats (g) & $62.1(28.2)$ & $64.2(32.6)$ & $58.9(23.0)$ & 0.013 & 1.000 & 1.000 \\
Carbohydrates (g) & $228(57.9)$ & $258(156)$ & $209(64.3)$ & 0.056 & 1.000 & 0.903
\end{tabular}

Note: Significant decrease in fruit intake was observed between the first diet record compared to both the second $(\mathrm{p}=0.007)$ and third $(\mathrm{p}=0.023)$ diet records using the repeated measures ANOVA test. No significant changes were observed for the other dietary variables ( $\mathrm{p}>0.05)$. *Denotes statistical significance, $\mathrm{p} \leq 0.05$.

Table 4.

Correlations Between the Average Number of Steps and Body Composition, Blood Pressure, Fasting Blood Glucose, and Waist-To-Hip Ratio Within Four Weeks (N=29)

\begin{tabular}{llll}
\hline Variable & Mean Value (SD) & $\begin{array}{l}\text { Pearson’s Correlation } \\
\text { with Mean Steps }\end{array}$ & P-Value \\
\hline Total body water & $0.325(0.041)$ & -0.287 & 0.184 \\
Fat mass (kg) & $0.279(0.092)$ & 0.281 & 0.195 \\
Fat free mass (kg) & $45.128(5.349)$ & 0.118 & 0.592 \\
Systolic blood pressure (mmHg) & $109.267(9.447)$ & -0.079 & 0.719 \\
Diastolic blood pressure (mmHg) & $71.474(7.329)$ & -0.032 & 0.885 \\
Fasting blood glucose (mg/dL) & $85.629(13.715)$ & 0.021 & 0.923 \\
Waist-to-hip ratio & $0.760(0.058)$ & 0.136 & 0.536 \\
\hline
\end{tabular}

\section{Discussion}

Waist and hip circumference and WHR decreased significantly at the end of study, suggesting that monitored walking through the use of a pedometer results in physical abdominal changes. The observed results support the first hypothesis that pedometer-metered walking results in decreased waist and hip circumference. Although conclusions cannot be drawn regarding the types of physical abdominal 
changes from the results, a trend towards significance $(p=0.06)$ was observed for FFM, suggesting that FFM may be decreasing and is likely the reason for the abdominal changes. Further pedometer-metered walking studies demonstrating significant decreases in FFM are needed in order to substantiate our observations.

A 6-week similar study with type 2 diabetics examined the effects of a pedometer-metered intervention on parameters found a trend towards significance for decreased waist measurements $\quad(p>0.05) \quad$ (Araiza, Hewes, Gashetew, Vella, \& Burge, 2006). Other studies investigating the body composition effects of pedometer-metered walking using overweight/obese subjects support the significant decreases in waist and hip measurements observed in this study (Lam, Lee, S. Wong, \& A. Wong, 2012; Soroush et al., 2015).

The significant decrease in fruit intake observed from the first diet records to the second and third diet records was an unexpected result. Our first hypothesis stated that a positive diet change would be observed due to pedometer-metered walking, which would be demonstrated as increased fruit intake rather than decreased fruit intake. Previous studies have shown that inadequate PA is associated with low fruit intake (Hahn et al., 2014; D. Silva \& R. Silva, 2015). Therefore, the results from this study were not consistent with similar research. There are several possibilities for why this decrease occurred, although none of the hypotheses can be supported and require additional research. It is possible that the fruit availability and selection decreased during the winter months of January and February, or that variety, and availability was responsible. It is possible that participant stress levels increased and affected diet choices. Previous research has supported that fruit intake is influenced by autonomous motivation as well as by social support, which are known to affect stress levels (McSpadden et al., 2016).

Fasting blood glucose and blood pressure results did not support our first hypothesis that pedometer-metered walking results in a decrease in those variables in apparently healthy adults. It is important to note that previous studies displaying decreases in fasting blood glucose levels following walking interventions have used diabetic adults as their subjects (Yamanouchi et al., 2002). Therefore, fasting blood glucose levels need to be assessed in walking intervention studies using apparently healthy non-diabetic adults. Previous research investigating the effects of walking on blood pressure in healthy adult subjects supports the study hypothesis that walking over time decreases blood pressure (Murtagh, Boreham, Nevill, Hare, \& Murphy, 2005). A possibility for why blood pressure did not decrease significantly in the study could be that the cardiovascular fitness level of the participants was at a high enough level prior to the intervention that would not result in a significant impact on blood pressure values.

A final conclusion to be drawn from the results is that external motivation provided through motivational quotes is not effective in increasing the number of steps walked per day. Our results did not support the second hypothesis that receiving motivational quotes would result in an increase in the number of steps walked per day, and it contradicts the previous research demonstrating that external motivation increases participation in PA (Dumitrescu \& Otoiu, 2014). Thus, subsequent studies are needed to explore the type of motivations needed, including the relationships of autonomous motivation and external motivation on step walking.

\section{Limitations}

Two major limitations exist in this study. The first limitation is the short study duration. Since walking is a low-intensity form of PA, health parameter changes may not occur in as little as four weeks. If the study had been expanded, significant health changes may have been observed over time.

The second limitation is the low number of subjects in the study. Statistical analysis could only be performed on a sample size of 29 for the anthropometric and intervention data, and the sample size was even less for the dietary data $(\mathrm{N}=20)$. The power for the paired-T test statistical analysis was $74 \%$, which is close to 
the level of adequate sample power (>75\%) (www.statpages.org, Iowa, USA). However, the power for the repeated measures ANOVA was lower than the acceptable sample power level at 49\% (www.statpages.org, Iowa, USA). The third limitation was the reliability of the self-reported three-day diet records, as they could contain human error (Lassale et al., 2015; Walker et al., 2013). The fourth limitation was an uneven distribution of male and female participants. Only two out of the twenty-nine participants who finished the current study were male, therefore gender differences could not be analyzed. More studies are needed to analyze differences in gender outcomes.

The participants in this study were apparently healthy in weight and were not overweight or obese. Research comparing the effects of pedometer-metered walking on healthy and overweight/obese participants is necessary to determine the effectiveness of using pedometers for increasing the number of steps walked per day for the general (healthy) populations. The results might have been significantly different if the subjects were overweight or obese. However, it is important to see if there is a difference observed in healthy populations first before trying a similar intervention in subjects of unhealthy weight.

\section{Conclusion}

In conclusion, pedometer-metered walking did not result in significantly increased fat free mass
(FFM), decreased fat mass, FBG or BP changes. There was a trend towards a significant decrease for FFM ( $p=0.06)$ at the end of the study in both groups. Additionally, fruit intake significantly decreased in both groups. More studies are needed to determine the reasons for this unexpected decrease, which reflect a negative change in diet choices.

However, WHR significantly decreased, suggesting that 4 weeks of pedometer walking results in physical abdominal changes. Our results support the use of pedometers as a method of increasing daily physical activity through walking to decrease waist and hip circumferences. We found that significant changes in WHR can occur over a 4-week time period in apparently healthy $(18.5<\mathrm{BMI}<25.0$ $\mathrm{kg} / \mathrm{m}^{2}$ ) adult individuals, suggesting that longer studies should be completed to determine if long-term pedometer-metered step walking results in additional body composition changes.

There were no differences between the MQ and control groups for increasing the number of steps walked per day, and no correlation was found between the average number of steps walked and body composition, FBG, BP, WHR, and diet choices. Additional research is needed to understand the relationship between pedometer-metered walking, motivation, and the effects on diet choices as well as body composition and metabolic changes over a longer period of time.

\section{References}

Aadland, E., Jepsen, R., Andersen, J. R., Anderssen, S. A. (2014). Differences in fat loss in response to physical activity among severely obese men and women. Journal of Rehabilitation Medicine, 46(4), 363-369. https://doi.org/10.2340/16501977-1786

Anderson, K. M, Odell, P. M., Wilson, P. W. F., Kannel, W. B. (1991). Cardiovascular disease risk profiles. American Heart Journal, 121(1), 293-298. http://dx.doi.org/10.1016/00028703(91)90861-B

Araiza, P., Hewes, H., Gashetew, C., Vella, C. A., Burge, M. R. (2006). Efficacy of a pedometer-based physical activity program on parameters of diabetes control in type 2 diabetes mellitus. Metabolism, 55(10), 1382-1387. http://dx.doi.org/10.1016/j.metabol.2006.06.009

Bakuradze, T., Parra, G. A. M., Riedel, A., et al. (2014). Four-week coffee consumption affects energy intake, satiety regulation, body fat, and protects DNA integrity. Food Research International, 63, 420-427. http://dx.doi.org/10.1016/j.foodres.2014.05.032 
Meeks, L., Reynaga, A., Worland, C., Jo, E., Dunn, S., Wien, M., Bums-Whitmore, B. / Californian Journal of Health Promotion 2017, Volume 15, Issue 1, 1-12.

Bond, B. J., Perry, A. C., Parker, L., Robinson, A., Burnett, K. (2002). Dose-response effect of walking exercise on weight loss. How much is enough? International Journal of Obesity and Related Metabolic Disorders, 26(11), 1484-1493. doi:10.1038=sj.ijo.0802133

Brunet, J., Gunnell, K. E., Gaudreau, P., Sabiston, C. M. (2015). An integrative analytical framework for understanding the effects of autonomous and controlled motivation. Personality and Individual Differences, 84, 2-15. http://dx.doi.org/10.1016/j.paid.2015.02.034

Burns-Whitmore, B., Haddad, E., Sabaté, J., Rajaram, S. (2014). Effects of supplementing n-3 fatty acid enriched eggs and walnuts on cardiovascular disease risk markers in healthy free-living lactoovo-vegetarians: a randomized, crossover, free-living intervention study. Nutrition Journal, 13(1), 29-37. doi:10.1186/1475-2891-13-29

Carlson, S. A., Fulton, J. E., Pratt, M., Yang, Z., Adams, E. K. (2015). Inadequate physical activity and health care expenditures in the United States. Progressive Cardiovascular Disease, 57(4), 315323. http://dx.doi.org/10.1016/j.pcad.2014.08.002

Dubinina, I. A., Chistiakov, D. A., Eremina, I. A., et al. (2014). Studying progression from glucose intolerance to type 2 diabetes in obese children. Diabetes and Metabolic Syndrome: Clinical Research and Reviews, 8(3), 133-137. http://dx.doi.org/10.1016/j.dsx.2014.07.002

Dumitrescu, R., \& Otoiu, A. (2014). Perceiving the value of practicing physical exercise as a positive motivation for students. Procedia-Social and Behavioral Sciences, 117(19), 729-734. http://dx.doi.org/10.1016/j.sbspro.2014.02.290

Edholm, D., Kullberg, J., Karlsson, F. A., Haenni, A., Ahlstrom, H., Sundbom, M. (2015). Changes in liver volume and body composition during 4 weeks of low calorie diet before laparoscopic gastric bypass. Surgery for Obesity and Related Diseases, 11(3), 602-606. http://dx.doi.org/10.1016/j.soard.2014.07.018

Gilson, N., McKenna, J., Puig-Ribera, A., Brown, W., Burton, N. (2009). The impact of route and incidental walking on waist circumference: a randomised workplace intervention. Journal of Science and Medicine in Sport, 12, S15. http://dx.doi.org.proxy.library.cpp.edu/10.1016/j.jsams.2008.12.039

Gupta, N., Balasekaran, G., Govindaswamy, V.V., Hwa, C.Y., Shun, L.M. (2011). Comparison of body composition with bioelectrical impedance (BIA) and dual energy x-ray absorptiometry (DEXA) among Singapore Chinese. Journal of Science and Medicine in Sport, 14(1), 33-35. http://dx.doi.org/10.1016/j.jsams.2010.04.005

Hahn, L. A., Galletly, C. A., Foley, D. L., et al. (2014). Inadequate fruit and vegetable intake in people with psychosis. Australian and New Zealand Journal of Psychiatry, 48(11), 1025-1035. doi:10.1177/0004867414553950

Haskell, W. L., Lee, I. M., Pate, R. R., et al. (2007). Physical activity and public health: updated recommendation for adults from the American College of Sports Medicine and the American Heart Association. Circulation, 116(9), 1081-1093. https://doi.org/10.1161/CIRCULATIONAHA.107.185649

Helmrich, S. P., Ragland, D. R., Leung, R. W., Paffenbarger, Jr. R. S. (1991). Physical activity and reduced occurrence of non-insulin-dependent diabetes mellitus. New England Journal of Medicine, 325(3), 147-152.

Hu, F. B., Sigal, R. J., Rich-Edwards, J. W., et al. (1999). Walking compared with vigorous physical activity and risk of type II diabetes in women: a prospective study. JAMA, 282(15), 1433-1439. doi:10.1001/jama.282.15.1433

Lam, S. C., Lee, L. Y. K., Wong, S. L., Wong, A. K. P. (2012). Pedometer-determined physical activity and body composition in Chinese working adults. Journal of Nursing Scholarship, 44(3), 205214. doi:10.1111/j.1547-5069.2012.01460.x

Lassale, C., Castetbon, K., Laporte, F., et al. (2015). Correlations between fruit, vegetables, fish, vitamins, and fatty acids estimated by web-based nonconsecutive dietary records and respective biomarkers of nutritional status. Journal of the Academy of Nutrition and Dietetics, 116, 427-438. http://dx.doi.org/10.1016/j.jand.2015.09.017 
Meeks, L., Reynaga, A., Worland, C., Jo, E., Dunn, S., Wien, M., Bums-Whitmore, B. / Californian Journal of Health Promotion 2017, Volume 15, Issue 1, 1-12.

McSpadden, K. E., Patrick, H., Oh, A. Y., Yaroch, A. L., Dwyer, L. A., Nebeling, L. C. (2016). The association between motivation and fruit and vegetable intake: the moderating role of social support. Appetite, 96, 87-94. http://dx.doi.org/10.1016/j.appet.2015.08.031

Mitchell, A. B., Cole, J. W., McArdle, P. F., et al. (2015). Obesity increases risk of ischemic stroke in young adults. Stroke, 46(6), 1690-1692. https://doi.org/10.1161/STROKEAHA.115.008940

Montesi, L., Moscatiello, S., Malavolti, M., Marzochhi, R., Marchesini, G. (2013). Physical activity for the prevention and treatment of metabolic disorders. Internal and Emergency Medicine, 8(8), 655-666. doi:10.1007/s11739-013-0953-7

Murtagh, E. M., Boreham, C. A. G., Nevill, A., Hare, L. G., Murphy, M. H. (2005). The effects of 60 minutes of brisk walking per week, accumulated in two different patterns, on cardiovascular risk. Preventive Medicine, 41, 92-97. http://dx.doi.org/10.1016/j.ypmed.2004.10.008

Parfitt, G., Olds, T., Eston, R. (2015). A hard/heavy intensity is too much: the physiological, affective, and motivational effects (immediately and 6 months post training) of unsupervised perpetually regulated training. Journal of Exercise Science and Fitness, 13(2), 123130. http://dx.doi.org/10.1016/j.jesf.2015.10.002

Rheaume, C., Arsenault, B. J., Faha, J. P. D., et al. (2014). Impact of abdominal obesity and systemic hypertension on risk of coronary heart disease in men and women: the EPIC-Norfolk population study. Journal of Hypertension, 32(11), 2224-2230. doi:10.1097/HJH.0000000000000307

Richardson, C. R., Newton, T. L., Abraham, J. J., Sen, A., Jimbo, M., Swartz, A. M. (2008). A metaanalysis of pedometer-based walking interventions and weight loss. Annals of Family Medicine, 6(1), 69-77. doi:10.1370/afm.761

Ritchie, J. D., Miller, C. K., Smiciklas-Wright, H. (2005). Tanita foot-to-foot bioelectrical impedance analysis system validated in older adults. Journal of the American Dietetic Association, 105(10), 1617-1619. http://dx.doi.org/10.1016/j.jada.2005.07.011

Silva, D. A. S., \& Silva, R. J. S. (2015). Association between physical activity level and consumption of fruit and vegetables among adolescents in northeast Brazil. Revista Paulista de Pediatria, 33(2), 167-173. http://dx.doi.org/10.1016/j.rpped.2014.09.003

Skelton, J. A., Cook, S. R., Auinger, P., Klein, J. D., Barlow, S. E. (2009). Prevalence and trends of severe obesity among U.S. children and adolescents. Academy of Pediatrics, 9(5), 322-329. http://dx.doi.org/10.1016/j.acap.2009.04.005

Slentz, C. A., Duscha, B. D., Johnson, J. L., et al. (2004). Effects of the amount of exercise on body weight, body composition, and measures of central obesity. Archives of Internal Medicine, 164(1):31-39. doi:10.1001/archinte.164.1.31

Soroush, A., Walker, J., Yngve, A., et al. (2015). The effects of a 6-month pedometer-determined physical activity intervention on body composition characteristics in Swedish adults: the ASUKI step study. International Journal of Body Composition Research, 10(2), 47-54. ISSN: 1479-456X

Stanely, D. M., Cumming, J., Standage, M., Duda, J. L. (2012). Images of exercising: exploring the links between exercise imagery use, autonomous and controlled motivation to exercise, and exercise intention and behavior. Psychology of Sport and Exercise, 13(2), 133-141. http://dx.doi.org/10.1016/j.psychsport.2011.10.002

Tieland, M., Van de Rest, O., Dirks, M. L., et al. (2012). Protein supplementation improves physical performance in frail elderly people: a randomized, double-blind, placebo-controlled trial. Journal of the American Medical Directors Association, 13(8), 720-726. http://dx.doi.org/10.1016/j.jamda.2012.07.005

Walker, J. L., Bell K. L., Boyd, R. N., Davies, P. S. W. (2013). Validation of a modified three-day weighed food record for measuring energy intake in preschool-aged children with cerebral palsy. Clinical Nutrition, 32(3):426-431. http://dx.doi.org/10.1016/j.clnu.2012.09.005

Wang, Y., Beydoun, M. A., Liang, L., Caballero, B., Kumanyika, S. K. (2008). Will all Americans become overweight or obese? Estimating the progression and cost of the U.S. obesity epidemic. Obesity, 16(10), 2323-2330. doi:10.1038/oby.2008.351

Wang, C. Y., McPherson, K., Marsh, T., Gortmaker, S. L., Brown, M. (2011). Health and 
economic burden of the projected obesity trends in the USA and the UK. Lancet (North American Edition), 378, 815-825. http://dx.doi.org/10.1016/S0140-6736(11)60814-3

World Health Organization. (2011). Waist Circumference and Waist-Hip Ratio. Report of a WHO Expert Consultation. Geneva, 8-11 December 2008. Geneva, Switzerland: WHO Press, World Health Organization.

Yamanouchi, K., Abe, R., Takeda, A., Atsumi, Y., Shichiri, M., Sato, Y. (2002). The effect of walking before and after breakfast on blood glucose levels in patients with type I diabetes treated with intensive insulin therapy. Diabetes Research and Clinical Practice, 58(1), 11-18. http://dx.doi.org/10.1016/S0168-8227(02)00099-2

\section{Acknowledgements}

Thanks to undergraduate students Andy Reynaga for collecting blood glucose data, Corinne Worland for collecting the waist and hip measurements, Laura Bradfield for collecting BP measurements, and Shanna Miller for helping with participant recruitment. Special thanks to Fernando Diaz and the Wellness Center Staff for allowing us to use their facility for data collection. We wish to thank the participants for their time and effort, and to Dr. David Still for project editing. This study was funded by Cal Poly Pomona through the California Wellness Grant (SEES Scholar) and the Research, Scholarship and Creative Activities (RSCA) program.

Corresponding Author:

Dr. Bonny Burns-Whitmore

Mailing Address: California State Polytechnic University, Pomona

3801 West Temple Ave, Pomona, CA, USA 91768

Telephone: 1-(805)-231-0864

Email: bburnswhitmo@cpp.edu 